\title{
Sistem Penunjang Keputusan Pembelian Smartphone Dengan Menggunakan Metode Fuzzy Tsukamoto
}

\author{
Aditya Anggun ${ }^{1}$, Fitri Marisa ${ }^{2}$, Indra Dharma ${ }^{3}$
}

\begin{abstract}
Fuzzy logic is one method to analyze system containing uncertainty. In this study used methods Tsukamoto Fuzzy. Designing a system for obtaining the output is done in three stages, namely Fuzzyfikasi, Inference, and defusifikasi. In this study defuzzyfication done using the method of weight average using the programming language PHP (Web-based). This study aims to produce an output value that can help the user to determine which smartphone will be purchased based on a specification. This method of checking and calculating the parameters that have been determined, then match it with the rules, and finally calculate the final value as a result of the assessment.

Inti sari - Logika fuzzy merupakan salah satu metode untuk melakukan analisis sistem yang mengandung ketidakpastian. Pada penelitian ini digunakan metode Fuzzy Tsukamoto. Perancangan sistem untuk memperoleh output dilakukan dalam 3 tahapan, yaitu Fuzzyfikasi, Inferensi, dan defusifikasi. Pada penelitian ini defuzzyfikasi dilakukan dengan menggunakan metode weight average dengan menggunakan bahasa pemrograman PHP (Berbasis Web). Penelitian ini bertujuan untuk menghasilkan suatu nilai output yang dapat membantu user untuk menentukan smartphone yang akan dibeli berdasarkan suatu spesifikasi. Metode ini memeriksa dan menghitung parameter-parameter yang telah ditentukan, kemudian mencocokkan dengan aturan-aturan, dan terakhir menghitung nilai akhir sebagai hasil penilaian.
\end{abstract}

Kata kunci: Sistem penunjang keputusan, Fuzzy Tsukamoto, Pembelian Smartphone, PHP, DBMS MySQL.

\section{A. Latar Belakang \\ I. PENDAHULUAN}

Perkembangan teknologi informasi dan komunikasi sangatlah cepat, sebagai akibat dari arus globalisasi. Salah satu perangkat teknologi informasi dan komunikasi yang mengalami perkembangan yang cepat adalah telepon seluler / handphone.

Smartphone yang dapat diartikan sebagai "telepon genggam yang pintar", merupakan sebuah alat komunikasi elektronik yang mempunyai kemampuan dasar yang sama dengan telepon konvensional saluran tetap (telepon kabel), namun dapat dibawa ke mana-mana (portabel, mobile) dan tidak perlu disambungkan dengan jaringan telepon menggunakan kabel (nirkabel; wireless). Sehingga kita dapat berkomunikasi dari sembarang tempat, selama masih ada jaringan sinyal untuk HP yang kita gunakan.

Dengan pendekatan sistem informasi, perekomendasian pembelian smartphone dapat dilakukan dengan memanfaatkan sistem pendukung keputusan yang telah dikembangkan.

Metode yang digunakan pada penelitian ini menggunakan Fuzzy Tsukamoto. Dengan metode ini diharapkan dapat dibuat sistem penunjang keputusan yang dapat merekomendasikan pembelian smartphone.

Ada beberapa logika fuzzy yang sudah dipelajari, namun perancangan menggunakan fuzzy tsukamoto dikarenakan penentuan model inference harus tepat. Fuzzy mamdani umumnya cocok untuk permasalahan intuitive, fuzzy sugeno untuk permasalahan yang menangani control, sedangkan fuzzy tsukamoto untuk rekomendasi. (Suyanto,2007)

Tujuan penelitian ini adalah Merancang dan mengimplementasikan sistem pendukung keputusan pembelian smartphone agar dapat membantu konsumen untuk menentukan pilihan smartphone yang akan dibeli.

\section{A. Definisi Smartphone}

\section{LANDASAN TEORI}

Smartphone atau bisa disebut dengan telepon pintar/cerdas sudah menjadi sebuah kebutuhan bagi sekian orang di dunia ini sebagai penunjang aktivitas kerja maupun sekedar lifestyle atau gaya hidup. Telepon cerdas (smartphone) adalah telepon genggam yang mempunyai kemampuan tingkat tinggi, kadangkadang dengan fungsi yang menyerupai komputer. Belum ada standar pabrik yang menentukan arti telepon cerdas. Bagi beberapa orang, telepon pintar merupakan telepon yang bekerja

${ }^{1}$ Mahasiswa, Universitas Widyagama, jln.Borobudur 35 Malang 65128 INDONESIA(telp: 08990304005 e-mail:

aditya.anggun.pradana@gmail.com) ${ }^{23}$ Dosen, Jurusan Teknik Informatika Fakultas Teknik Universitas Widyagama, jln.Borobudur 35 Malang 65128 INDONESIA (e-mail :fitrimarisa@widyagama.ac.id) 
menggunakan seluruh perangkat lunak sistem operasi yang menyediakan hubungan standar dan mendasar bagi pengembang aplikasi. Kebanyakan alat yang dikategorikan sebagai telepon pintar menggunakan sistem operasi yang berbeda. Dalam hal fitur, kebanyakan telepon pintar mendukung sepenuhnya fasilitas surel dengan fungsi pengatur personal yang lengkap. Fungsi lainnya dapat menyertakan miniatur papan ketik QWERTY, layar sentuh atau D-pad, kamera, pengaturan daftar nama, penghitung kecepatan, navigasi piranti lunak dan keras, kemampuan membaca dokumen bisnis, pemutar musik, penjelajah foto dan melihat klip video, penjelajah internet, atau hanya sekedar akses aman untuk membuka surel (surat elektronik) perusahaan, seperti yang ditawarkan oleh BlackBerry. Fitur yang paling sering ditemukan dalam telepon pintar adalah kemampuannya menyimpan daftar nama sebanyak mungkin, tidak seperti telepon genggam biasa yang mempunyai batasan maksimum penyimpanan daftar nama. (Jocom, 2013).

\section{B. Sistem Penunjang Keputusan}

Sistem Penunjang Keputusan (SPK) adalah bagian dari sistem informasi berbasis komputer termasuk sistem berbasis pengetahuan untuk mendukung pengambilan keputusan dalam suatu organisasi atau perusahaan (Marsani, 2010). Pada dasarnya konsep DSS hanyalah sebatas pada kegiatan membantu para manajer melakukan penilaian serta menggantikan posisi dan peran manajer. Sistem pendukung keputusan adalah bagian dari sistem informasi berbasis komputer (termasuk sistem berbasis pengetahuan) yang dipakai untuk mendukung pengambilan keputusan dalam suatu organisasi atau perusahaan, dapat juga dikatakan sebagai sistem komputer yang mengolah data menjadi informasi untuk mengambil keputusan dari masalah semi-terstruktur yang spesifik (Hanif, 2011).

\section{Logika Fuzzy}

Menurut (Kusumadewi \& Hari , 2004), logika fuzzy adalah suatu cara yang tepat untuk memetakan suatu ruang input kedalam suatu ruang output, mempunyai nilai kontinyu. Fuzzy dinyatakan dalam derajat dari suatu keanggotaan dan derajat dari kebenaran. Oleh sebab itu sesuatu dapat dikatakan sebagian benar dan sebagian salah pada waktu yang sama. Sistem logika fuzzy terdiri dari himpunan fuzzy dan aturan fuzzy. Subset fuzzy merupakan himpunan bagian yang berbeda dari variabel input dan output.

\section{Fuzzy Tsukamoto}

Pada metode Tsukamoto, setiap aturan direpresentasikan menggunakan himpunan-himpunan fuzzy, dengan fungsi keanggotaan yang monoton. Untuk menentukan nilai output crisp/hasil yang tegas (Z) dicari dengan cara mengubah input (berupa himpunan fuzzy yang diperoleh dari komposisi aturanaturan fuzzy) menjadi suatu bilangan pada domain himpunan fuzzy tersebut. Cara ini disebut dengan metode defuzzifikasi (penegasan). Metode defuzzifikasi yang digunakan dalam metode Tsukamoto adalah metode defuzzifikasi rata-rata terpusat/berbobot (Center Average Defuzzyfier). (Kusumadewi \& Hari , 2004).

Misalkan ada 2 variabel input, $\mathrm{x}$ dan $\mathrm{y}$, serta variabel output yaitu z. Variabel x terbagi atas 2 himpunan yaitu A1 dan A2. variabel y terbagi atas 2 himpunan B1 dan B2, sedangkan variabel output $\mathrm{z}$ terbagi atas 2 himpunan yaitu $\mathrm{C} 1$ dan $\mathrm{C} 2$. Tentu saja himpunan yang bersifat monoton. Ada 2(dua) aturan yang digunakan sebagai berikut:

[R1] IF $\mathrm{x}$ is $\mathrm{A} 1$ and $\mathrm{y}$ is $\mathrm{B} 2 \mathrm{THEN} \mathrm{z}$ is $\mathrm{C} 1$

[R2] IF $x$ is $A 2$ and $y$ is $B 1$ THEN $z$ is $C 2$

$\alpha$-predikat untuk aturan pertama dan kedua, masing-masing adalah $\alpha 1$ dan $\alpha 2$, dengan menggunakan penalaran monoton, diperoleh nilai z1 pada aturan pertama dan z2 pada aturan kedua.

\section{E. Penegasan (Defuzzyfication)}

Proses defuzzifikasi adalah konversi dari harga-harga fuzzy menjadi harga crisp. Suatu himpunan fuzzy diperoleh dari komposisi aturan-aturan fuzzy, sedangkan output yang dihasilkan merupakan suatu bilangan pada domain himpunan fuzzy, sehingga jika diberikan himpunan fuzzy dalam range tertentu, maka harus dapat diambil suatu nilai crips tertentu sebagai output. Oleh karena itu defuzzifikasi dilakukan dengan menggunakan defuzzifikasi weight average karena metode ini digunakan untuk fungsi keanggotaan keluaran yang simetris.

$$
\mathrm{Z}=\frac{\alpha_{1}{ }^{*} z_{1}+\alpha_{2} * z_{2}+\alpha_{3} * z_{3}+\ldots+\alpha_{n} * z_{n}}{\alpha_{1}+\alpha_{2}+\alpha_{3}+\ldots+\alpha_{n}}
$$

\section{ANALISIS DAN PERANCANGAN SISTEM}

A. DFD level $O$ (diagram konteks) SPK Pembelian Smartphone.

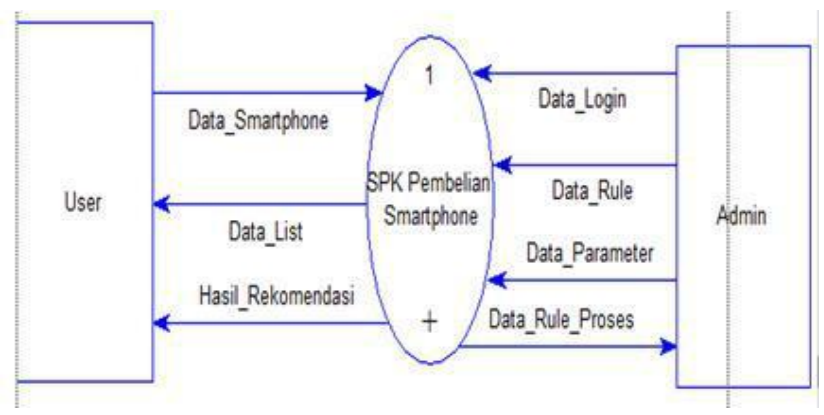

Gbr.1 Contoh DFD level 0 SPK kelayakan Produk Contoh 
B. DFD level 1 (diagram 0) SPK kelayakan produk contoh

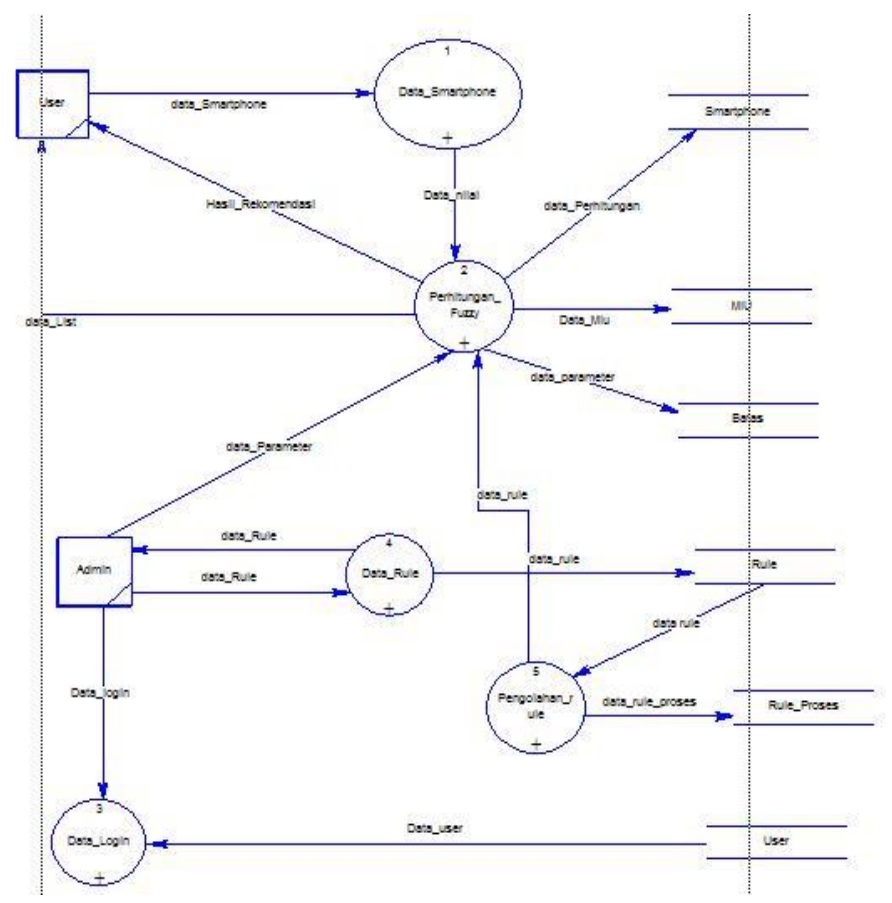

Gbr.2 Contoh DFD level 1 SPK Pembelian Smartphone

C. Analisis Metode

Dari gambaran umum sistem dapat dijabarkan lagi lebih detail menjadi rincian proses yang mana digambarkan pada gambar berikut ini :

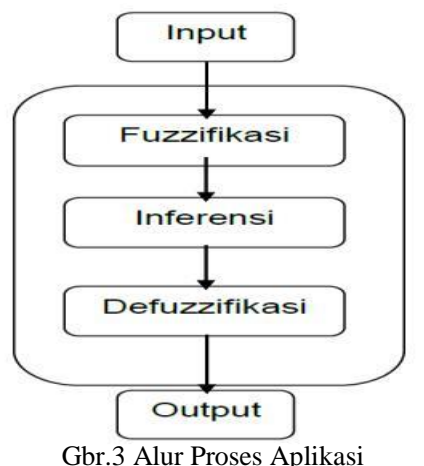

Berdasarkan gambar di atas maka dapat dijelaskan alur proses sistem adalah sebagai berikut :

1. Membaca inputan dari user.

2. Dari inputan yang diterima maka akan dilakukan proses fuzzifikasi. Yaitu mencari nilai keanggotaan dengan menggunakan fungsi keanggotaan himpunan fuzzy dengan memperhatikan nilai maksimum dan minimum dari tiap variabel.
3. Selanjutnya dilakukan proses inferensi.

4. Setelah proses inferensi maka akan dilakukan proses defuzzifikasi, yaitu untuk menentukan output crisp menggunakan defuzzifikasi rata-rata terpusat.

5. Selanjutnya hasil perhitungan ditampilkan kepada user.

D. Fuzzyfikasi

Fuzzifikasi merupakan tahap pertama dari proses inferensi fuzzy. Pada tahap ini data masukan diterima dan sistem menentukan nilai fungsi keanggotaannya serta mengubah variabel numerik (variabel non fuzzy) menjadi variabel linguistik (variabel fuzzy).

Dalam tahap ini akan dilakukan perhitungan dengan menggunakan rumus seperti dibawah ini :

$$
\text { MAX }=\frac{\frac{x-\min }{\max -\min }}{\max -x}
$$$$
\text { Fuzzifikasi MAX }
$$$$
\mathrm{MIN}=\max -\min
$$

\section{E. Proses Inferensi}

Inferensi adalah penggabungan banyak aturan berdasarkan data yang tersedia. Perlu dipahami, bahwa tiap-tiap aturan pada basis pengetahuan fuzzy akan berhubungan dengan suatu relasi fuzzy. Bentuk umum dari aturan yang digunakan dalam fungsi implikasi adalah :

IF $x$ is A THEN $y$ is $B$

Dengan $\mathrm{x}$ dan y adalah scalar, dan A dan B adalah himpunan fuzzy. Proposisi yang mengikuti IF disebut sebagai anteseden, sedangkan proposisi yang mengikuti THEN disebut sebagai konsekuen.

\section{F. Defuzzyfikasi}

Alur proses defuzzifikasi dapat dilihat pada gambar dibawah :

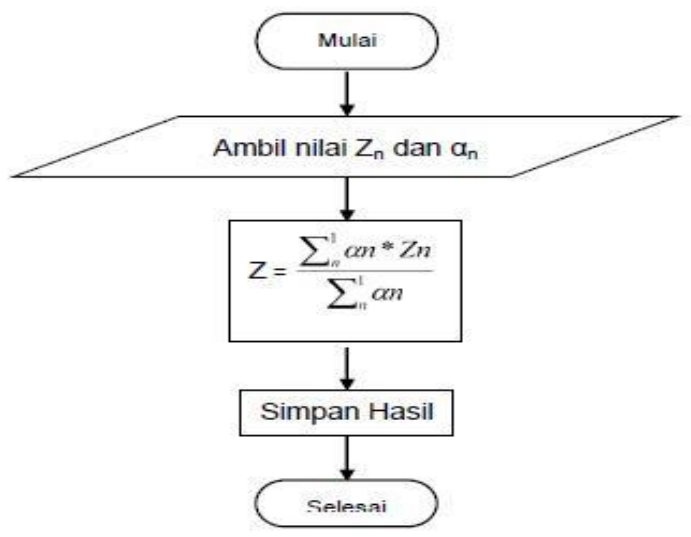

Gbr.4 Flow Chart Proses Defuzzyfikasi 
Berdasarkan gambar di atas maka dapat dijelaskan alur proses defuzzifikasi adalah sebagai berikut :

1. Mulai proses.

2. Mengambil nilai $\mathrm{Zn}$ dan $\alpha$.

3. Menghitung nilai $Z$ sebagai hasil akhir proses defuzzifikasi.

4. Simpan hasil.

\section{HASIL DAN PENGUJIAN}

\section{A. Menu Halaman Utama}

Halaman utama program ini terdiri dari 4 menu utama yang terdapat di bagian kanan atas, yaitu beranda, rekomendasi, tentang, dan login.

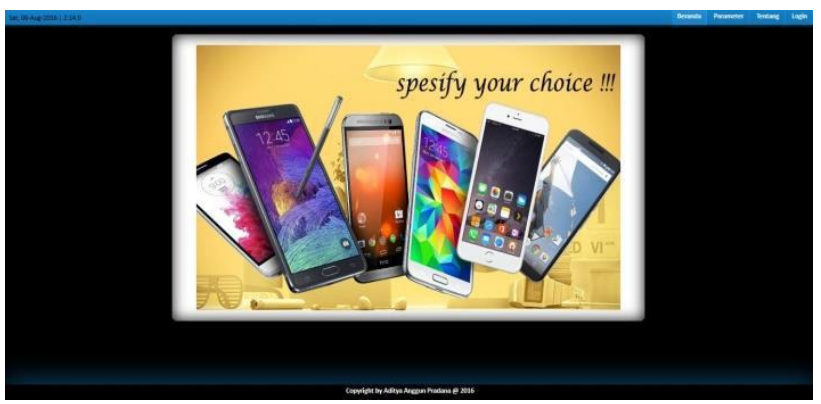

Gbr.5 Halaman Utama

\section{B. Menu Rekomendasi}

Halaman ini digunakan untuk melakukan input spesifikasi maupun melihat list smartphone yang sudah ada pada sistem. Halaman ini menampilkan parameter sistem serta proses button untuk menampilkan hasil rekomendasi sistem.

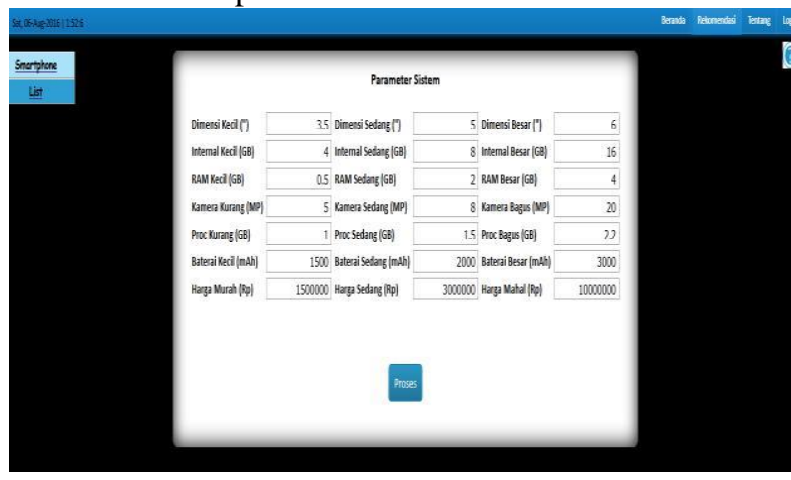

Gbr.6 Menu Rekomendasi

\section{Menu Input Smartphone}

Menu ini berfungsi untuk memasukan data smartphone.

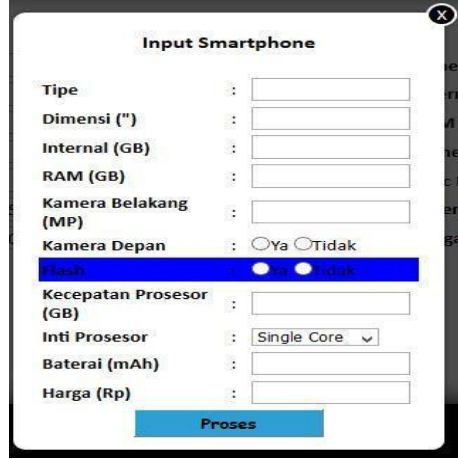

Gbr.7 Menu Input Smartphone

D. Proses SPK Fuzzy Tsukamoto

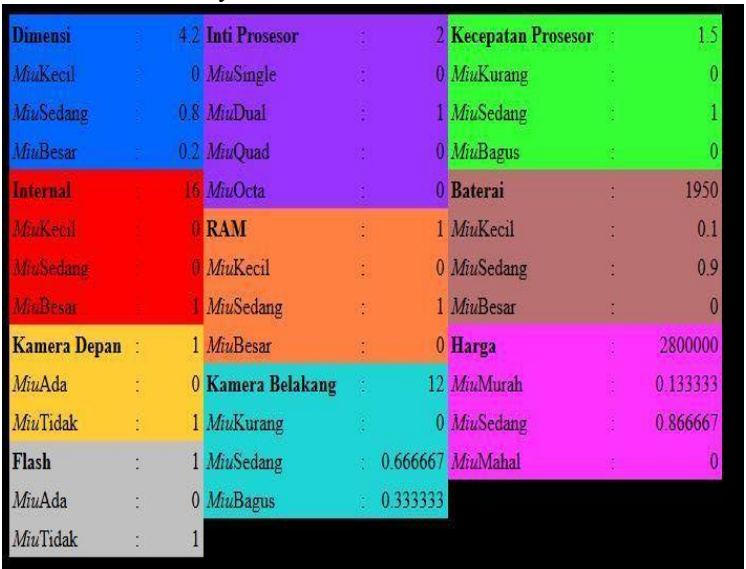

Gbr. 8 Proses Fuzzifikasi

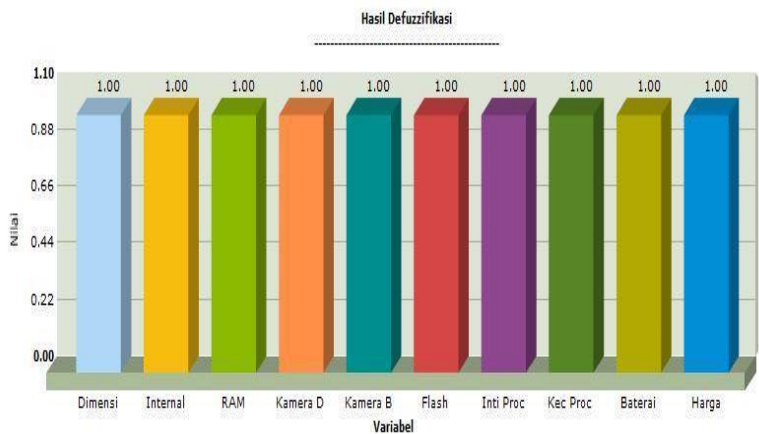

Total Alfa $=1.07$

Total Alfa ${ }^{*} \mathrm{z}=94$

Hasil Defuzzifikasi $=88.13$

Nilai rekomendasi untuk Smatphone ini sebesar $=88.13$

Gbr.9 Hasil Defuzzifikasi 


\section{E. Proses SPK Fuzzy Tsukamoto}

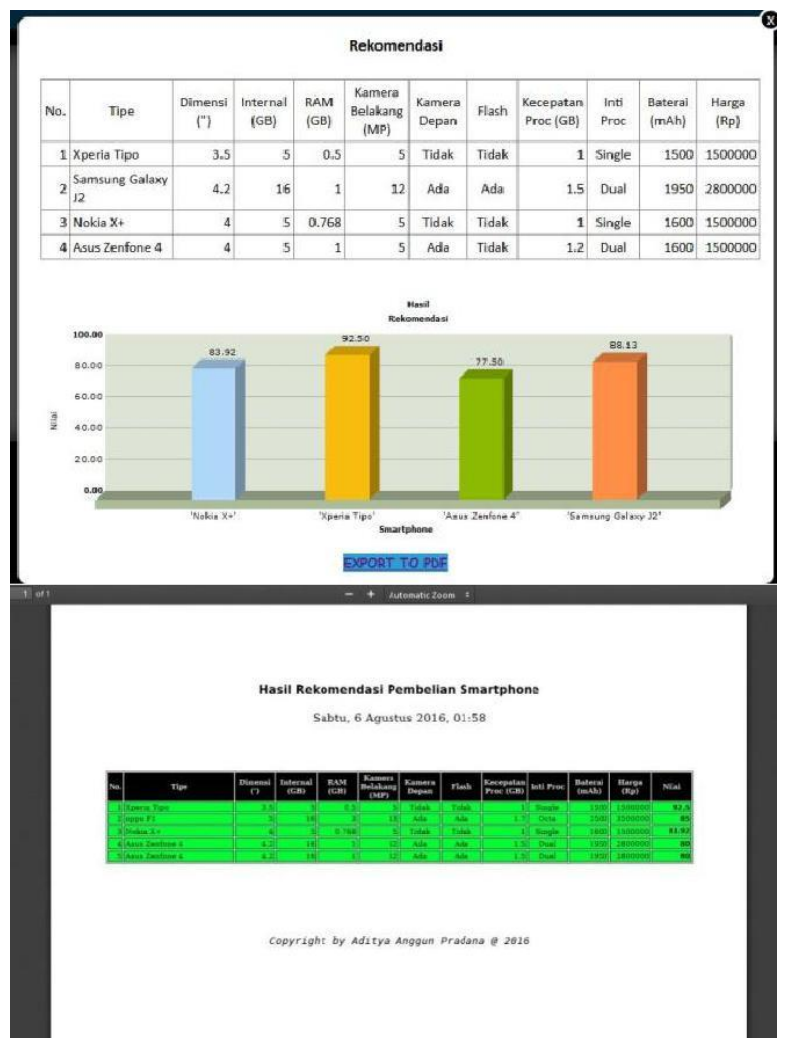

\section{A. Kesimpulan}

\section{KESIMPULAN DAN SARAN}

Berdasarkan permasalahan yang ada pada Sistem Penunjang Keputusan Pembelian Smartphone dapat disimpulkan sebagai berikut :

1. Dapat memberikan keputusan/ rekomendasi tentang perbandingan smartphone yang akan dibeli berdasarkan spesifikasi yang diinput.

2. Inputan dari user dapat diproses melalui tiga tahapan, yaitu fuzzifikasi, inferensi, dan defuzzifukasi sehingga menghasilkan suatu nilai rekomendasi.

3. Metode defuzzifikasi pada fuzzy tsukamoto adalah defuzzifikasi rata-rata terpusat.

4. Variabel yang mempunyai pengaruh paling besar terhadap nilai rekomendasi adalah dimensi, baterai, dan harga, dilanjutkan internal, RAM, dan kamera belakang.

\section{B. Saran}

Adapun saran dari penyusun skripsi diharapkan dapat lebih meningkatkan hasil yang telah didapatkan adalah sebagai berikut :
1. Adapun saran dari penyusun skripsi diharapkan dapat lebih meningkatkan hasil yang telah didapatkan adalah sebagai berikut :

2. Menambahan parameter agar sistem bisa memberikan hasil yang lebih detail.

3. Menambah rule yang ada di sistem agar nilai yang dihasilkan lebih akurat.

4. Memperbaiki interface program dan mengembangkan interface lebih interaktif dan memudahkan user.

5. Menerapkan dalam bahasa pemrograman lain, misalnya Android, C++, Java, dan sebagainya.

\section{REFERENSI}

[1] Cox, E. (1994). The Fuzzy Systems Handbook Handbook Prsctitioner's Guide to Building, Using, and Maintaining.

Academic Press.

[2] Frans Susilo, S. (2006). Himpunan dan Logika Kabur serta Aplikasinya. Yogyakarta: Graha Ilmu.

Hanif. (2011). Sistem Penunjang Keputusan Dalam Menentukan Kinerja Sales Obat Herbal.

[3] Hartini, D. C., Endang , L., \& Ali , I. (2013). Sistem Pendukung Keputusan Pemilihan Hotel Di Kota Palembang Dengan Metode Simple Additive Weighting (SAW). Jurnal Sistem Informasi (JSI), 546-565.

[4] Irawan, P., Zanial, M., \& Febriyanti , P. (2015). Penerapan Metode Fuzzy Tsukamoto dalam Sistem Pendukung Keputusan Pemilihan Karyawan Terbaik. SC-SITI.

[5] Jocom, N. (2013). Peran Smartphone Dalam Menunjang Kinerja Karyawan Bank Prismadana (Studi Pada Karyawan Bank Prismadana Cabang Airmadidi). Acta Diurna, 7-8.

[6] Kusumadewi. (2006). Fuzzy Multi-Atribute Decision Making (Fuzzy MADM). Yogyakarta: Graha ilmu.

Kusumadewi, S. (2002). Analisis Desain Sistem Fuzzy Menggunakan Tool Box. Matlab. Jogjakarta: Graha Ilmu.

[7] Kusumadewi, S., \& Hari , P. (2004). Aplikasi Logika Fuzzy untuk Mendukung Keputusan. Yogyakarta: Graha Ilmu.

Marsani. (2010). Sistem Penunjang Keputusan Seleksi Mahasiswa Berprestasi Menggunakan Metode AHP. STIMIK ICC.

[8] Maryaningsih, Siswanto, \& Mesterjon. (2013). METODE LOGIKA FUZZY TSUKAMOTO DALAM SISTEM PENGAMBILAN KEPUTUSAN PENERIMAAN BEASISWA. Media Infotama, 9, 142.

[9] Setiadji. (2009). Himpunan dan Logika Samar serta Aplikasinya. Yogyakarta: Graha Ilmu. 
[10] Sholihin, M., Nurul, F., \& Nurul , K. (2013). Sistem Pendukung Keputusan Penentuan Warga Penerima Jamkesmas Dengan Metode Fuzzy Tsukamoto. Jurnal Teknika.

[11] Suyanto. (2007). Artificial Intelegent;

Searching,Reasoning, Planing, and Learning. Bandung: Informatika. 